\section{ORIGIN AND SHAPE}

The Surface of the Earth

By Arthur L. Bloom. (Foundations of Earth Science Series.) Pp. viii + 152. (Prentice-Hall: Englewood Cliffs, New Jersey and London, 1969.) $25 s$.

THIs well illustrated book is one of the "Foundations of Earth Science Series", a closely integrated sequence of ten introductory texts on the natural environment. The aim is to provide brief, readable, up to date summaries of all aspects of earth science. Arthur Bloom, in The Surface of the Earth, amply fulfils this objective. He takes a scientific approach and, without ever becoming excessively mathematical or pedantic, provides a stimulating general outline, with occasional intimate detail and frequent reference to new concepts. He has been admirably helped by his publishers as the print, design and diagrams are pleasing and the price seems very reasonable.

The contents discuss in successive chapters the available energy supply, and the various processes that act on rocks at the Earth's surface; the movement of debris downslope, especially in water channels; the sequential evolution of a landscape as the degradation proceeds; the geomorphic changes at coastlines; and the work of glaciers in modifying existing landforms and creating new.

In spite of the width of the subject and economy of space, the author often adds interesting details, and it is good to see in an introductory book lucid discussions of topics such as pressure-release in rocks, soil classification, stream velocity, and pediments. The text is commendably lively and faultless, and "principle" for "principal" (page 46) underlines the desirably analytical method. The beginner can have few excuses for misunderstanding and will find many enticing avenues open to him.

The seasoned geomorphologist will find much to praise and little to carp at. Suggestions inevitably arise. The account of the movement of ground water in arid areas stresses the effect of surface evaporation and capillarity whereas the upward movement must be due entirely or largely to pressure head in the aquifer. The long and interesting discussions of grade and on the downstream increase in the mean velocity of rivers are based on modern findings, but it is doubtful whether beginners will be able to grasp fully their geomorphic application. The introduction into a scientific treatise of Davisian ideas on "youthful" and "mature" valleys or rivers seems rather an unnecessary and feeble complication, particularly when the author admits that "we evaluate the stage of sequential evolution of individual valleys independent of the stage of evolution of the regional landscape". Similarly, the omission in the long profile of a glacier bed of overdeepenings, especially in the cirque, seems a quite unnecessary simplification.

R. P. Beckinsale

\section{ANOMALOUS ABUNDANCE}

The Structure and Properties of Water

By D. Eisenberg and W. Kauzmann. Pp. xii +296 . (Clarendon Press: Oxford; Oxford University Press: London, March 1969.) $65 s$.

ArThough water is the most abundant compound on the surface of the Earth and the principal constituent of all living organisms, many of its physical properties are anomalous and some unique. It is generally agreed that its unusual behaviour arises from structural or configurational effects which result from the formation of hydrogen bonds between adjacent water molecules; however, agreement ends there, for estimates of the degree of hydrogen bonding and its temperature and pressure dependence range widely. In spite of considerable research in this field during the past decade, progress in solving the puzzle of the structure of water has been slow.

In their book, the authors have summarized most of the experimental and theoretical work which is relevant to the problem of elucidating the structure of water and have reviewed and assessed the progress that has been made. The opening chapter is devoted to a description of the isolated water molecule based, first, on what is deduced from experiment and, second, on what is predicted by the application of the electronic theory of chemical valence. 'This is followed by a summary of the thermodynamic properties of steam and a discussion of these properties in terms of interactions between the water molecules. 'The structure of ice and its various polymorphs is presented in detail, together with an outline of their thermodynamic, electrical and spectroscopic properties. A brief discussion of the role of hydrogen bonding in determining the structure of ice concludes this section. The remaining and most important half of the book is concerned with the properties of liquid water and the various models that have been proposed to represent its structure. No attempt has been made to discuss all the physical properties; only those which are known to be strongly structure dependent have been considered. Detailed attention is given to infrared and Raman spectra because these measurements provide direct evidence of the structure of water. Surprisingly, the authors have chosen to omit any discussion of the properties of aqueous solutions although such studies provide much valuable information on molecular interactions in liquids.

The book will be of great value to all scientists interested in water and sufficient basic physical chemistry has been included in the text to make it comprehensible to those who have studied chemistry or physics to first degree level. A noteworthy feature of the excellent presentation is the provision of a number of large tables which are printed on folded sheets to facilitate comparison of various measured or predicted properties. The text is supplemented by an addendum which, in the main, describes and lists papers which were published too late for the results to be incorporated in the main work. The usefulness of the book is augmented by a bibliography which lists more than four hundred reforences and the compilation of a comprehensive author and subject index.

K. E. BETT

A. HaRLOW

\section{MATTER WITHOUT TEARS}

\section{Chemistry}

A. Study of Matter. By Alfred B. Garrett, W. T. Lippincott and Frank Henry Verhoek. Pp. viii + 722. (Blaisdell (Ginn): Waltham, Mass., and London, December 1968.) \$11.75.

THE first impressions created of this book are good. First class production and good layout make it easy to read although it is rather heavy. Useful summaries are provided with each chapter and additional material is presented in bold typo as "super" footnotes without interrupting the narrative. Questions are open-ended and will prompt reference to other books. The quotations with each chapter add interest, pin-pointing the debt we owe to the great scientists of the past. Fortunately, translations are provided for passages from Mendeleev, van der Waals and others.

A detailed reading of the book does not always live up to expectations. Many misconceptions are perpetuated; for example, the implication that the dipole moments of hydrogen halides are due to the polarity of the bond. No indication is given of the nature of the parent species for the weak base properties of ammonia solutions. Most inorganic chemists will disagree that $\mathrm{BF}_{3}$ is electron deficient and carbonyls are $\pi$-complexes. Many diagrams 